Published in final edited form as:

Curr Opin Oncol. 2010 May ; 22(3): 250-256. doi:10.1097/CCO.0b013e328337a5d2.

\title{
Recent Updates in Renal Cell Carcinoma
}

\author{
W. Kimryn Rathmell and Paul A Godley \\ Department of Medicine, Division of Hematology and Oncology, Lineberger Comprehensive Cancer \\ Center, University of North Carolina, Chapel Hill, NC 27599
}

\section{Abstract}

Purpose of Review-This review will examine the recent advances in our understanding of the genetic and molecular events that shape this cancer, and overview the emerging targeted therapies that have altered the landscape for renal cell carcinoma (RCC) patients.

- The incidence of RCC continues to rise, making it the $7^{\text {th }}$ and $8^{\text {th }}$ most common cancer among men and women in the U.S., respectively.

- VHL loss is an important factor in the development of clear cell RCC, however:

Loss of VHL can result in tumors which express both HIF1 and HIF2, or HIF2 alone, correlating with distinct pathway activities

Invasive tumors demonstrating loss of VHL consistently demonstrate additional genetic changes, which appear to be essential for tumor progression.

- Targeted therapies have demonstrated improvements in overall survival

- New ways to radiographically measure the tumor response to these treatments may provide additional information about a drug's activity in an individual patient.

- VEGF receptor TKIs are still being investigated in the adjuvant setting.

Summary-The field of RCC biology continues to rapidly change. As new targeted strategies to control this cancer evolve, so do both the clinical strategies, and the strategies to measure response and predict outcome.

\section{Keywords}

Renal Cell Carcinoma; Von Hippel-Lindau; Hypoxia Inducible Factor; Birt-Hogg-Dube; Vascular Endothelial Growth Factor; Tyrosine Kinase Inhibitor; Mammalian Target of Rapamycin

\section{Introduction}

Renal cell carcinoma continues to rise in incidence and garner increased attention as new biological and therapeutic details emerge for this once obscure cancer. The biology of RCC relevant to clear cell histology disease still hinges on VHL mutation as an important initiating event in most tumors. Similarly, the landscape for RCC treatment has changed dramatically in recent years, with the addition in 2009 of three new FDA-approved agents for RCC.

\footnotetext{
Address Correspondence to: W. Kimryn Rathmell, MD, PhD, 450 West Drive, CB 7295, Lineberger Cancer Center, Room 21-237, Chapel Hill, NC 27599, TEL: (919) 966-3522, FAX: (919) 966-8212, Rathmell@ med.unc.edu.

Publisher's Disclaimer: This is a PDF file of an unedited manuscript that has been accepted for publication. As a service to our customers we are providing this early version of the manuscript. The manuscript will undergo copyediting, typesetting, and review of the resulting proof before it is published in its final citable form. Please note that during the production process errors may be discovered which could affect the content, and all legal disclaimers that apply to the journal pertain.
} 


\section{Epidemiology and factors contributing to renal cell carcinoma}

Renal cell carcinoma continues to represent an increasing proportion of the cancer landscape. This year 58,000 new cases of RCC are expected in the U.S., reflecting a continued increase in incidence [1]. This steady rise, continuing over the past 20 years, to a large extent reflects an increase in the radiographic identification of incidental masses. However, RCC mortality has not declined in that time frame, implying that the increase in diagnoses is not solely due to early detection. As a result of this steady increase, and the declines seen in other cancers, RCC has risen to become the $7^{\text {th }}$ most common cancer in men and the $8^{\text {th }}$ most common cancer in women in the U.S. [1] (Figure 1). In all, one in 70 individuals will be diagnosed with this cancer.

\section{Advances in genetics and biology of renal cell carcinoma}

Recent advances in the biology of RCC include increased demonstration of VHL-associated molecular features. A recent study by Gordan, et al, demonstrated three subgroups of clear cell tumors: those with wild type VHL (which lacked widespread expression of HIF1 or HIF2), and those harboring VHL mutation or hypermethylation, which were further subdivided into HIF1/HIF2-expressing and HIF2-expressing tumors. Although the impact on tumor behavior is uncertain, the effect of these molecular phenotypes on tumor gene expression and pathway activation was remarkable, with VHL mutant/HIF2 tumors in particular demonstrating activation of myc signaling and defects in normal cell cycle regulation [2], Further, a gene expression and genomic analysis of sporadic and VHL disease-associated renal masses found a high degree of similarity between the VHL disease tumors and a homogenous subgroup of the sporadic tumors. This analysis, which demonstrated $3 p$ chromosomal losses in virtually every tumor, also importantly demonstrated a consistency of losses and gains of genetic material, which may be valuable for future therapeutic development [3]. Finally, an analysis of cytogenetics demonstrated chromosomal aberrations with a high degree of consistency with these observations, which were correlated with patients' survival. Losses at chromosome $3 p$ were largely associated with favorable outcome as has been suggested previously, whereas losses in regions of chromosomes $4 \mathrm{q}, 9 \mathrm{p}$, and $14 \mathrm{q}$ were particularly associated with poor risk [4].

Looking to specific genes involved in RCC, recent mouse models demonstrated the relevance of common genes associated with heritable renal cancer syndromes across animal species. The folliculin gene has been linked to the Birt-Hogg-Dube syndrome, predisposing to chromophobe RCC and oncocytoma [5]. In work by Hartman, et al. a mouse model of folliculin loss demonstrated the spontaneous development of cysts and tumors resembling oncocytoma [6] [7]. This animal model represents the first legitimate genetically engineered mouse model of any of the RCCs, and will hopefully pave the way for other model systems, which can be useful for guiding the development of therapeutic and diagnostic strategies. In a model of VHL disease, our group engineered a VHL gene missense mutation which displayed a predisposition for renal tumor formation following chemical mutagenesis with a potent alkylating agent (Figure 2) [8]. This model of VHL-induced renal tumorigenesis suggests the essential need for additional genetic events to promote renal tumorigenesis, similar to the observations in patient samples that demonstrate significant (and predictable) genetic events coinciding with VHL loss.

\section{Detection of renal cell carcinoma}

Computed tomography (CT) has been a mainstay of renal mass detection for many years. With the increased resolution of scans, particularly with the current generation of contrast agents, the potential to use densitometry and three-dimensional measurements to evaluate the kidney has led to several new and important advances. First, computer assisted radiology tools can 
permit highly consistent measurements of kidney tumor 3D geometry and enhancement. Such a strategy demonstrated a significant capability to distinguish between cysts and small renal masses in patients with hereditary renal carcinoma syndromes [9], and could be particularly valuable to correctly assign the increasing number of incidentally detected small renal lesions or provide accurate surveillance of such masses that have low metastatic potential.

A second application of this kind of re-analysis of conventional CT imaging examines intratumoral density as a measure of disease response to therapy. Similar strategies were employed to analyze conventional contrast-enhanced CT images for changes in tumor density, demonstrating correlation with both uni-dimensional tumor response and progression-free survival for patients treated with VEGF pathway-targeted agents [10] [11]. An example of this densitometric change in a primary tumor is demonstrated in Figure 3. Further standardization of the method for quantifying these measurements is required, but ultimately such threedimensional measures of disease response may represent a more accurate quantification of response to therapeutics.

\section{Management of localized disease}

The management of localized disease, particularly for small renal masses, has continued to evolve. With the advent of robotic laparoscopic surgery for bladder and prostate cancers, it is not surprising that this is also being extended to localized renal masses. This approach is gaining popularity; with good oncologic outcomes expected for most patients with small renal masses, the selection of a particular treatment approach becomes a matter of considering co-morbidities and other factors. The National Cancer Institute has applied the robotic approach to partial laparoscopic nephrectomy for multiple tumors, largely focused on patients with heritable renal cancer syndromes, and has found that this approach is promising and worthy of further investigation [12]. Further, this technique has provided the opportunity to dispense with clamping the renal hilum, a particularly important consideration for patients predisposed to developing renal carcinoma, who can anticipate repeated interventions over their lifetime.

As these surgical approaches have evolved, so have ablative therapies, as well as the appreciation that many small lesions may have low metastatic potential. This topic, complicated by multiple modalities of ablative therapy and the lack of definitive radiographic strategies to discern dangerous small lesions from indolent masses, has been thoroughly reviewed [13]. Ultimately, comparative studies are required to demonstrate the assumed equivalence of these strategies.

\section{Adjunctive therapy}

Adjuvant and neoadjuvant treatments for RCC represent an important opportunity for reducing the risk of disease recurrence, and potentially expanding the group of patients cured of this cancer.

\section{Adjuvant therapy}

Historically, adjuvant trials of cytokine-based therapies have been disappointing, demonstrating lack of improvement over surgical treatment alone, or in some cases trends toward shortened survival $[14,15]$. Recent efforts to implement novel strategies of immune system modulation have been the first to demonstrate a potential for improved outcome. In the 10-year survival analysis of a study of autologous tumor lysate vaccine adjuvant therapy, a trend was demonstrated toward increased survival in all patients, with a statistically significant improvement observed for patients with T3 tumors. In multivariate analysis, the T3 tumor subgroup continued to demonstrate improved survival, $\mathrm{HR}=1.67, \mathrm{p}=0.011$ [16]. In a move toward advancing targeted anti-angiogenesis therapy to the adjuvant setting, a small study was 
performed at MD Anderson Cancer Center exploring the use of adjuvant thalidomide. Fortysix patients were enrolled to a randomized study of observation vs. thalidomide $300 \mathrm{mg}$ daily for 24 months. Unfortunately, the two- and three-year cancer-specific survivals were not improved with treatment, and the thalidomide-treated patients actually had poorer survival at two and three years $(47.8 \%$ vs $69.3 \%$ and $28.7 \%$ vs $69.3 \%$, respectively; $\mathrm{P}=.022)$ [17].

Much attention is being focused on several ongoing studies testing the adjuvant use of VEGFreceptor tyrosine kinase inhibitor (TKI) therapy. Despite the failure of thalidomide to demonstrate activity in this venue, evidence from the metastatic disease setting suggests that the VEGF-receptor TKIs are much more potent against RCC. Multiple studies are ongoing and anticipated to complete enrollment in the coming year. These studies include: the ASSURE study, randomizing patients with completely resected clear cell tumor larger than $4 \mathrm{~cm}$ to 1 year of sunitinib, sorafenib, or placebo, at conventional doses; the SORCE study, randomizing completely resected RCC tumors (any histology) in Europe that are intermediate or high risk according to the Leibovich score [18] to one year or three years of sorafenib at standard dose, or placebo; and finally, a smaller study comparing standard dose sunitinib to placebo (randomized 2:1) (Table 1). While these studies will take time to fully mature, they will provide immediate demonstration of the acute and longer term side effects of prolonged therapy in otherwise quite healthy individuals, and ultimately represent the most promising avenue of potential risk reduction for patients facing high risk for recurrence. As exciting as these strategies are, a complete analysis of adverse events and risk reduction is lacking, and such treatments at this time should be reserved exclusively for clinical trials.

\section{Neoadjuvant}

With drugs that can induce initial tumor shrinkage, it has become relevant to determine whether implementation of pre-operative treatment can impact primary tumors to reduce tumor bulk prior to surgery. Such an intervention may permit less invasive surgical approaches, or render "unresectable" disease "resectable," or provide an opportunity to gain control of systemic disease prior to removal of the primary mass. Several studies have begun to evaluate these approaches. The use of bevacizumab was investigated in the pre-operative setting for patients undergoing cytoreductive nephrectomy. This study of 50 patients demonstrated responses in the primary tumor, but led to wound dehiscence in three patients, likely due to the long halflife of the antibody [19]. Retrospective studies of a variety of VEGF pathway targeted agents with widely varied durations of therapy prior to surgery demonstrated the approach was feasible [20,21]. Sunitinib treatment until best response was employed in 19 patients with inoperable tumors, with four proceeding to nephrectomy without encountering any unexpected surgical morbidity [22]. A prospective study using sorafenib in a $4-8$ week window prior to surgery and continuing to within 48 hours of surgery defined the safety risks, which were minimal, and demonstrated a response in the primary tumor similar to that observed for systemic disease [23]. This study also highlighted the necessity for pretreatment biopsy, as two of the 30 patients on the study were found at nephrectomy to have non-renal cell primary tumors. Overall, these approaches are rational to consider for selected patients, appear to pose minimal risk for decline in performance status for surgery, and can achieve responses in primary tumors. Further investigation is necessary to determine the patient groups most likely to benefit from neoadjuvant therapy, and whether risk for disease recurrence can be reduced. In addition, the optimal duration of treatment prior to surgery needs to be defined.

\section{Recent advances in systemic therapy for metastatic disease}

VEGF receptor TKIs and drugs that inhibit mTOR signaling have become the mainstay for the management of metastatic disease based on improved progression-free survival or/and overall survival outcomes. 


\section{VEGF pathway inhibition}

Sunitinib has emerged as the current standard of care for first line therapy for patients with good or intermediate risk clear cell RCC. However, sorafenib remains an appropriate first line choice for selected patients, and recently pazopanib has received FDA approval, adding a third agent in this crowded field. Now, with prolonged experience and exposure to these drugs, new questions are emerging with regard to late side effects, disease control issues, and causes of disease resistance. These issues are being investigated with new insights into the etiology and mechanism of cardiac toxicity related to sunitinib. It is apparent that patients with pre-existing hypertension and coronary heart disease compose the group at greatest risk for encountering these effects [24]. Preclinical analysis suggests that sunitinib may be directly toxic to cardiac myocytes [25]. Moreover, the lasting effects of sunitinib exposure to endothelial and other tissues remain largely unknown. It is concerning that administration of high dose IL-2 after sunitinib failure has demonstrated a high incidence of severe cardiac toxicity, suggesting that damage may remain for some time after TKI therapy is discontinued [26]. Ultimately, what is becoming clear is the need to aggressively manage toxicities in order to maintain patients on optimally dosed therapy and avoid detrimental long-term complications [27,28].

Effective disease control has been inferred from significant improvements in progression-free survival. Now with more substantial follow up, the front-line study of sunitinib vs. interferon has demonstrated an overall survival benefit ( $26.4 \mathrm{v} 21.8$ months, $\mathrm{p}=0.51$ ), even in the setting of $65 \%$ of the interferon patients crossing over to receive sunitinib or another VEGF pathway targeted agent [29]. This survival benefit is modest, but suggests that additional consideration to questions such as when to initiate therapy (early vs late) may be important to investigate formally.

How RCCs initially responding to treatment with VEGF TKI therapy eventually develop resistance to these drugs is also garnering considerable interest. Understanding resistance mechanisms may allow strategies to delay or overcome resistance. Kinase mutations that cause resistance to drugs like imatinib do not appear to play a role here. Ongoing studies suggest angiogenic escape mechanisms may contribute to this process [30]. One intriguing experiment examining xenografts resistant to sorafenib demonstrates that they regain sensitivity when transplanted into new hosts [31]. How adapted strategies of drug delivery, schedule, or combination therapy may eliminate this problem is of utmost concern.

\section{mTOR pathway inhibition}

An alternate mechanism of targeted therapy for RCC is the inhibition of mTOR signaling via disruption of the mTORC1 complex. While the activities of mTOR inhibitors (temsirolimus and everolimus being the only rapalogues approved for RCC) on cancer cells remains an active area of investigation, we have learned how to strategically place them in the treatment of RCC patients. In the front line setting, temsirolimus has continued to be the mainstay for patients with poor risk disease, given the improvement in overall survival and it's good side effect profile [32]. This year everolimus was approved based on a study that evaluated this drug after disease progression on one or both VEGF receptor TKIs [33,34]. Patients demonstrated a doubling of progression-free survival. Thus, the mTOR pathway provides an ideal scenario for switching drug classes upon disease progression. Ongoing and future studies are actively exploring the appropriateness of switching drug classes upon disease progression.

\section{Combination strategies}

Efforts to enhance efficacy by combining two or more agents has employed two basic approaches. "Vertical inhibition" describes combinations of therapies that target factors working in a linear signaling pathway, as opposed to "Lateral inhibition" which implies inhibiting targets from non-overlapping pathways [35]. The first example of vertical inhibition 
demonstrated that maximally inhibiting the VEGF signaling pathway with bevacizumab inhibition of soluble VEGF ligand in combination with inhibition of VEGF receptor signaling with sorafenib could increase response rate, but at the expense of increased toxicity [36]. Whether an improved response rate translates into improvement in progression-free or overall survival is an active area of investigation.

Lateral inhibition takes the form of combinations of VEGF targeted agents and mTOR inhibitors. The combination of sunitinib with temsirolimus unfortunately demonstrated unacceptable toxicity, particularly a high incidence of microangiopathic hemolytic anemia [37]. Bevacizumab has been amenable to combinations in many settings, and tolerable doses have been identified for combination with temsirolimus; an ongoing study is evaluating the bevacizumab/temsirolimus combination vs. bevacizumab/interferon. Other ongoing combinations of RCC targeted therapies with chemotherapy, cytokine therapy, or novel agents remain the realm of clinical trials. These studies ultimately will need to address competing values of tumor response vs. tumor control vs. prolongation of survival vs. drug related side effects in the context of combination as opposed to sequential single agent therapies.

\section{Conclusion}

The field of renal cell carcinoma biology and management continues to evolve. The biology relevant to clear cell histology disease continues to hinge on VHL mutation as an important initiating event in most tumors. However, important nuances have emerged. First, the disease pathophysiology may hinge more on the end effect of VHL inactivation (deregulation of both HIF1 and HIF2 or HIF2 alone). Thus, where VHL has failed to emerge as an important biomarker, the end effect on the HIF transcription factor profile may dictate tumor biology critical to therapeutic response or overall disease behavior. Additionally, work from human tumor samples and mouse models suggest that not only secondary events occur, but are necessary for tumor progression. Further studies of human tumor genetic loci and signal transduction pathways affected in this cancer which supplement VHL mutation will be essential to generating realistic animal models, and may be effective for designing and utilizing targeted therapy for expanded benefit in renal cell carcinoma.

The landscape for renal cell carcinoma treatment has changed dramatically in recent years, with the addition of three new FDA-approved agents this year. This brings our arsenal to seven drugs: interleukin-2, the VEGF receptor TKI's sunitinib, sorafenib, and pazopanib, the VEGF neutralizing antibody bevacizumab in combination with interferon, and the mTOR inhibitors temsirolimus and everolimus. As new targeted strategies to control renal cell carcinoma evolve, so do the strategies to measure response and predict outcome.

Finally, how best to tailor the sequential use of these agents remains an object of intense scrutiny, although regular updates of the NCCN guidelines (with two updates in 2009) endeavor to provide guidance as new therapeutic options emerge [38]. The use of targeted therapies in combination, or as adjuncts to nephrectomy, are interesting but limited to clinical studies with the exception of highly unique clinical scenarios.

\section{Acknowledgments}

Dr. Rathmell has received research funding from Bayer/Onyx, participated in advisory boards and consulted for Novartis, and participated in an advisory board for AVEO. She is supported by the Doris Duke Charitable Fund. Dr. Godley is supported by National Center on Minority Health and Health Disparities Grant 1P60MD00244, National Cancer Institute Grant 1U01CA114629, and Department of Defense Grant PC060911. He participates on Data Monitoring Committees for Glaxo Smith Kline and Ferring Pharmaceuticals. 


\section{References}

1. Cancer Facts and Figures 2009. American Cancer Society, Inc: 10. 2009.

2. Gordan JD, Lal P, Dondeti VR, Letrero R, Parekh KN, Oquendo CE, Greenberg RA, Flaherty KT, Rathmell WK, Keith B, et al. HIF-alpha effects on c-Myc distinguish two subtypes of sporadic VHLdeficient clear cell renal carcinoma. Cancer Cell 2008;14:435-446. [PubMed: 19061835] *This study demonstrates three subgroups of clear cell tumors: those with wild type VHL, and those with HIF1/ HIF2-expressing and HIF2-expressing tumors harboring VHL mutation or hypermethylation. The findings suggest molecular criteria for selecting targeted therapies.

3. Beroukhim R, Brunet JP, Di Napoli A, Mertz KD, Seeley A, Pires MM, Linhart D, Worrell RA, Moch $\mathrm{H}$, Rubin MA, et al. Patterns of gene expression and copy-number alterations in von-hippel lindau disease-associated and sporadic clear cell carcinoma of the kidney. Cancer Res 2009;69:4674-4681. [PubMed: 19470766]

4. Klatte T, Rao PN, de Martino M, LaRochelle J, Shuch B, Zomorodian N, Said J, Kabbinavar FF, Belldegrun AS, Pantuck AJ. Cytogenetic profile predicts prognosis of patients with clear cell renal cell carcinoma. J Clin Oncol 2009;27:746-753. [PubMed: 19124809] ** This cytogenetic study demonstrates that genetic information from easily obtainable technology, such as the loss of chromosome 9, can add additional prognostic information to standard clinicopathologic findings.

5. Nickerson ML, Warren MB, Toro JR, Matrosova V, Glenn G, Turner ML, Duray P, Merino M, Choyke $\mathrm{P}$, Pavlovich CP, et al. Mutations in a novel gene lead to kidney tumors, lung wall defects, and benign tumors of the hair follicle in patients with the Birt-Hogg-Dube syndrome. Cancer Cell 2002;2:157164. [PubMed: 12204536]

6. Hasumi Y, Baba M, Ajima R, Hasumi H, Valera VA, Klein ME, Haines DC, Merino MJ, Hong SB, Yamaguchi TP, et al. Homozygous loss of BHD causes early embryonic lethality and kidney tumor development with activation of mTORCl and mT0RC2. Proc Natl Acad Sci USA 2009;106:1872218727. [PubMed: 19850877]

7. Hartman TR, Nicolas E, Klein-Szanto A, Al-Saleem T, Cash TP, Simon MC, Henske EP. The role of the Birt-Hogg-Dube protein in mTOR activation and renal tumorigenesis. Oncogene 2009;28:15941604. [PubMed: 19234517]

8. Lee CM, Hickey MM, Sanford CA, McGuire CG, Cowey CL, Simon MC, Rathmell WK. VHL Type 2B gene mutation moderates HIF dosage in vitro and in vivo. Oncogene 2009;28:1694-1705. [PubMed: 19252526]

9. Linguraru MG, Yao J, Gautam R, Peterson J, Li Z, Linehan WM, Summers RM. Renal Tumor Quantification and Classification in Contrast-Enhanced Abdominal CT. Pattern Recognit 2009;42:1149-1161. [PubMed: 19492069]

10. van der Veldt AAM, Meijerink MR, van den Eertwegh AJM, Haanen JBAG, Boven E. Choi response criteria for early prediction of clinical outcome in patients with metastatic renal cell cancer treated with sunitinib. Am. J. Roentgenography. 2009 In press.

11. Cowey CL, Fielding JR, Rathmell WK. The Loss of Radiographic Enhancement in Primary Renal Cell Carcinoma Tumors Following Multi-targeted Receptor Tyrosine Kinase Therapy is an Additional Indicator of Response. Urology. 2009 In press. *The measurement of intratumoral density of contrast-enhanced CT images can correlate with progression-free survival and may be able to serve as an indicator of disease response to RCC therapy.

12. Boris R, Proano M, Linehan WM, Pinto PA, Bratslavsky G. Initial experience with robot assisted partial nephrectomy for multiple renal masses. J Urol 2009;182:1280-1286. [PubMed: 19683275]

13. Chen DY, Uzzo RG. Optimal management of localized renal cell carcinoma: surgery, ablation, or active surveillance. J Natl Compr Canc Netw 2009;7:635-642. quiz 643. [PubMed: 19555585]

14. Messing EM, Manola J, Wilding G, Propert K, Fleischmann J, Crawford ED, Pontes JE, Hahn R, Trump D. Phase III study of interferon alfa-NL as adjuvant treatment for resectable renal cell carcinoma: an Eastern Cooperative Oncology Group/Intergroup trial. J Clin Oncol 2003;21:12141222. [PubMed: 12663707]

15. Clark JI, Atkins MB, Urba WJ, Creech S, Figlin RA, Dutcher JP, Flaherty L, Sosman JA, Logan TF, White R, et al. Adjuvant high-dose bolus interleukin-2 for patients with high-risk renal cell carcinoma: a cytokine working group randomized trial. J Clin Oncol 2003;21:3133-3140. [PubMed: 12810695] 
16. May M, Brookman-May S, Hoschke B, Gilfrich C, Kendel F, Baxmann S, Wittke S, Kiessig ST, Miller K, Johannsen M. Ten-year survival analysis for renal carcinoma patients treated with an autologous tumour lysate vaccine in an adjuvant setting. Cancer Immunol Immunother. 2009 Oct 30; [Epub ahead of print].

17. Margulis V, Matin SF, Tannir N, Tamboli P, Shen Y, Lozano M, Swanson DA, Jonasch E, Wood CG. Randomized trial of adjuvant thalidomide versus observation in patients with completely resected high-risk renal cell carcinoma. Urology 2009;73:337-341. [PubMed: 18950837]

18. Leibovich BC, Cheville JC, Lohse CM, Zincke H, Frank I, Kwon ED, Merchan JR, Blute ML. A scoring algorithm to predict survival for patients with metastatic clear cell renal cell carcinoma: a stratification tool for prospective clinical trials. J Urol 2005;174:1759-1763. discussion 1763. [PubMed: 16217278]

19. Jonasch E, Wood CG, Matin SF, Tu SM, Pagliaro LC, Corn PG, Aparicio A, Tamboli P, Millikan RE, Wang X, et al. Phase II presurgical feasibility study of bevacizumab in untreated patients with metastatic renal cell carcinoma. J Clin Oncol 2009;27:4076-4081. [PubMed: 19636008]

20. Thomas AA, Rini BI, Stephenson AJ, Garcia JA, Fergany A, Krishnamurthi V, Novick AC, Gill IS, Klein EA, Zhou M. Surgical resection of renal cell carcinoma after targeted therapy. J Urol 2009;182:881-886. [PubMed: 19616232]

21. Amin C, Wallen E, Pruthi RS, Calvo BF, Godley PA, Rathmell WK. Preoperative tyrosine kinase inhibition as an adjunct to debulking nephrectomy. Urology 2008;72:864-868. [PubMed: 18684493]

22. Thomas AA, Rini BI, Lane BR, Garcia J, Dreicer R, Klein EA, Novick AC, Campbell SC. Response of the primary tumor to neoadjuvant sunitinib in patients with advanced renal cell carcinoma. J Urol 2009;181:518-523. discussion 523. [PubMed: 19100579]* An example of the feasibility of neoadjuvant sunitinib therapy in patients with unresectable renal cell carcinoma. In this small study, at a median follow-up of 6 months, 4 patients $(21 \%)$ had undergone nephrectomy and 5 died of disease progression.

23. Cowey CL, Amin C, Pruthi RS, Wallen EM, Nielsen ME, Grigson G, Watkins C, Nance KV, Crane J, Jalkut M, et al. A Neoadjuvant Clinical Trial with Sorafenib for Patients with Stage II or Greater Renal Cell Carcinoma. J Clin Oncol. 2010 In Press.

24. Di Lorenzo G, Autorino R, Bruni G, Carteni G, Ricevuto E, Tudini M, Ficorella C, Romano C, Aieta M, Giordano A, et al. Cardiovascular toxicity following sunitinib therapy in metastatic renal cell carcinoma: a multicenter analysis. Ann Oncol 2009;20:1535-1542. [PubMed: 19474115]

25. Chintalgattu V, Patel SS, Khakoo AY. Cardiovascular effects of tyrosine kinase inhibitors used for gastrointestinal stromal tumors. Hematol Oncol Clin North Am 2009;23:97-107. viii-ix. [PubMed: 19248973]

26. Cho DC, Puzanov I, Regan MM, Schwarzberg T, Seery V, Lee MY, Liu V, Bhatt R, Koon H, Mier JW, et al. Retrospective analysis of the safety and efficacy of interleukin-2 after prior VEGF-targeted therapy in patients with advanced renal cell carcinoma. J Immunother 2009;32:181-185. [PubMed: 19238017]

27. Shepard DR, Garcia JA. Toxicity associated with the long-term use of targeted therapies in patients with advanced renal cell carcinoma. Expert Rev Anticancer Ther 2009;9:795-805. [PubMed: 19496716]

28. Robert C, Mateus C, Spatz A, Wechsler J, Escudier B. Dermatologic symptoms associated with the multikinase inhibitor sorafenib. J Am Acad Dermatol 2009;60:299-305. [PubMed: 19028406]

29. Motzer RJ, Hutson TE, Tomczak P, Michaelson MD, Bukowski RM, Oudard S, Negrier S, Szczylik C, Pili R, Bjarnason GA, et al. Overall survival and updated results for sunitinib compared with interferon alfa in patients with metastatic renal cell carcinoma. J Clin Oncol 2009;27:3584-3590. [PubMed: 19487381] This report of a randomized, phase III trial updates the progression-free survival results showing the superiority of sunitinib over interferon alfa. Sunitinib also demonstrated longer overall survival compared with interferon alfa.

30. Rini BI, Atkins MB. Resistance to targeted therapy in renal-cell carcinoma. Lancet Oncol 2009;10:992-1000. [PubMed: 19796751]

31. Panka D, Kumar M, Schor-Bardach R, Atkins M. Mechanism of acquired resistance to sorafenib in RCC. AACR Proceedings. 20082500. 
32. Bhatia S, Thompson JA. Temsirolimus in patients with advanced renal cell carcinoma: an overview. Adv Ther 2009;26:55-67. [PubMed: 19172239]

33. Motzer RJ, Escudier B, Oudard S, Hutson TE, Porta C, Bracarda S, Grunwald V, Thompson JA, Figlin RA, Hollaender N, et al. Efficacy of everolimus in advanced renal cell carcinoma: a doubleblind, randomised, placebo-controlled phase III trial. Lancet 2008;372:449-456. [PubMed: 18653228] ** In this phase III, randomised, double-blind, placebo-controlled trial of everolimus in patients with metastatic renal cell carcinoma, patients who had progressed on sunitinib, sorafenib, or both had double the progression-free survival on everolimus relative to placebo.

34. Oudard S, Medioni J, Aylllon J, Barrascourt E, Elaidi RT, Balcaceres J, Scotte F. Everolimus (RAD001): an mTOR inhibitor for the treatment of metastatic renal cell carcinoma. Expert Rev Anticancer Ther 2009;9:705-717. [PubMed: 19496707]

35. Sosman JA, Puzanov I, Atkins MB. Opportunities and obstacles to combination targeted therapy in renal cell cancer. Clin Cancer Res 2007;13:764s-769s. [PubMed: 17255307]

36. Sosman J, Puzanov I. Combination targeted therapy in advanced renal cell carcinoma. Cancer 2009;115:2368-2375. [PubMed: 19402058]

37. Fischer, P.; Patel, P.; Carducci, MA.; McDermott, DF.; Hudes, GR.; Lubiniecki, GM.; Gelder, MS.; Senico, P.; Curiel, RE.; Motzer, RJ. Phase I study combining treatment with temsirolimus and sunitinib malate in patients with advanced renal cell carcinomaP; ASCO Annual Meeting Proceedings; 2008. p. 16020

38. Clinical Recommendations: NCCN Clinical Practice Guidelines in Oncology. Kidney Cancer. Journal of the National Comprehensive Cancer Network 2009;7 
Male

Prostate (25\%)

Lung (15\%)

Colon (10\%)

Bladder (7\%)

Melanoma (5\%)

Non-Hodgkin Lymphoma (5\%)

Kidney (5\%)

Leukemia (3\%)

Oral Cavity (3\%)

Pancreas (3\%) $\underset{\text { Breast }(27 \%)}{\text { Female }}$

Lung (14\%)

Colon (10\%)

Uterus (6\%)

Non-Hodgkin Lymphoma (4\%)

Melanoma (4\%)

Thyroid (4\%)

Kidney (3\%)

Ovary (3\%)

Pancreas (3\%)

Figure 1.

New cases of renal cell carcinoma make up 5\% of cancers in males, $3 \%$ in females. Adapted with permission from [1]. 

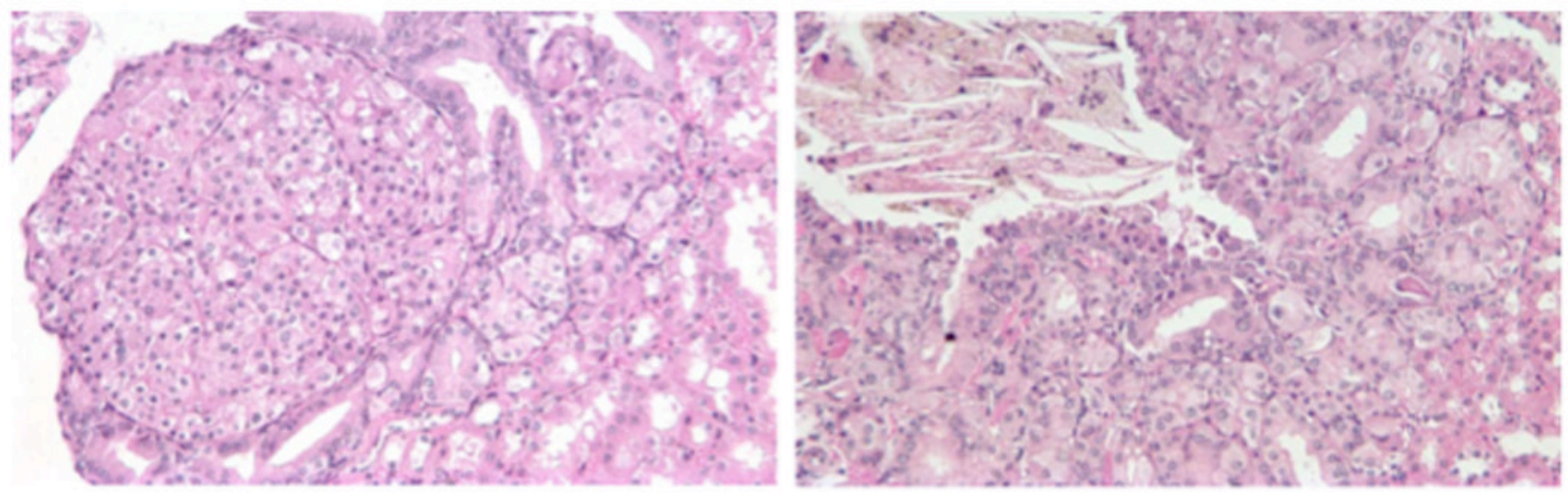

Figure 2.

Examples of renal neoplasms arising in the kidney of genetically engineered mice following treatment with ethyl nitrosourea. Adapted with permission from [8]. 


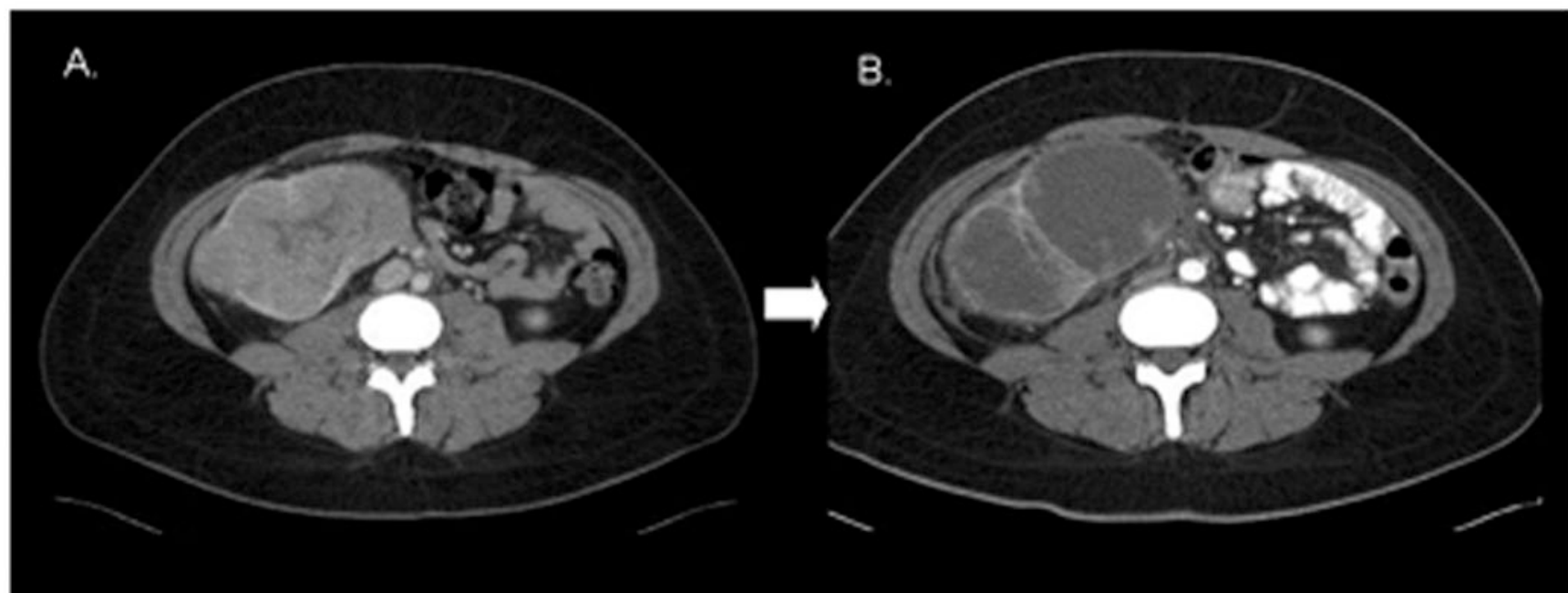

C.

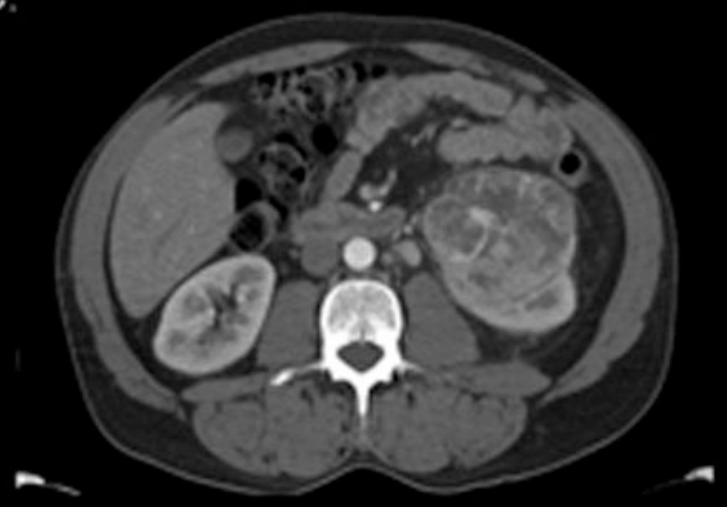

D.

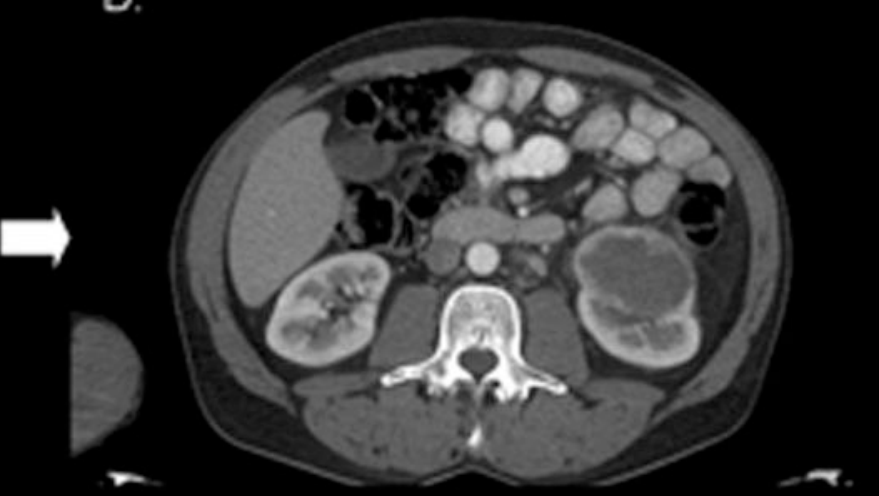

Figure 3.

Radiographic Responses to Neoadjuvant Sorafenib Therapy. A. Patient A with a large rightsided RCC prior to therapy. B. Patient A following 59 days of sorafenib therapy with significant intratumoral necrosis. C. Patient B with a prominent left-sided RCC, pretreatment. D. Patient $\mathrm{B}$ after 37 days of sorafenib with downstaging from $\mathrm{T} 2$ to $\mathrm{T} 1$. 
Table 1

Adjuvant studies for intermediate or high risk resected renal cell carcinoma

\begin{tabular}{|l|l|l|l|l|}
\hline $\begin{array}{l}\text { Adjuvant } \\
\text { Study }\end{array}$ & Inclusion Criteria & $\begin{array}{l}\text { Planned } \\
\text { Enrollment }\end{array}$ & Treatment Plan & $\begin{array}{l}\text { Outcome } \\
\text { Measures }\end{array}$ \\
\hline ASSURE (ECOG & $\begin{array}{l}\text { T1b disease } \\
\text { Any histology }\end{array}$ & 1923 & $\begin{array}{l}\text { Sunitinib vs } \\
\text { Sorafenib vs } \\
\text { Placebo (1 year) }\end{array}$ & $\begin{array}{l}\text { Disease-free } \\
\text { survival }\end{array}$ \\
\hline SORCE & $\begin{array}{l}\text { Leibovich score 3-11 } \\
\text { Any histology }\end{array}$ & 1656 & $\begin{array}{l}\text { Sorafenib 3 yr vs } \\
\text { Sorafenib 1yr vs } \\
\text { placebo }\end{array}$ & $\begin{array}{l}\text { Disease-free } \\
\text { survival }\end{array}$ \\
\hline S-TRAC & $\begin{array}{l}\text { UISS high risk } \\
>50 \% \text { clear cell }\end{array}$ & 236 & $\begin{array}{l}\text { Sunitinib 1 yr vs } \\
\text { placebo (2:1) }\end{array}$ & $\begin{array}{l}\text { Disease-free } \\
\text { survival }\end{array}$ \\
\hline
\end{tabular}

